(Q)

\title{
Voice of Mountain People Capacity Building of Community- based Organisations in Advocacy in the Hindu Kush-Himalayas
}

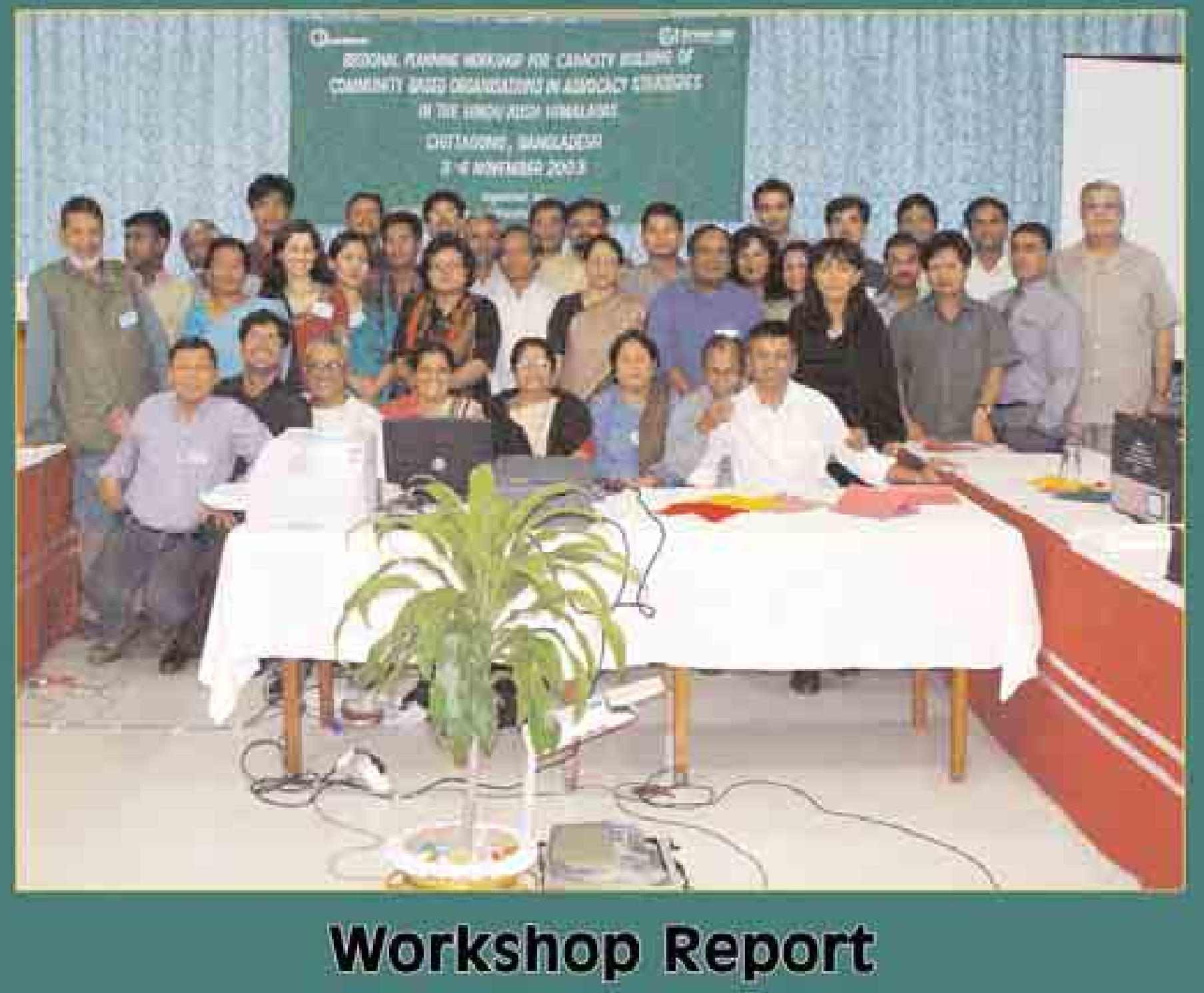




\section{About ICIMOD}

The International Centre for Integrated Mountain Development (ICIMOD) is an independent Mountain Learning and Knowledge Centre serving the eight countries of the Hindu Kush-Himalayas - Afghanistan $\cdots$, Bangladesh $\bullet$, Bhutan

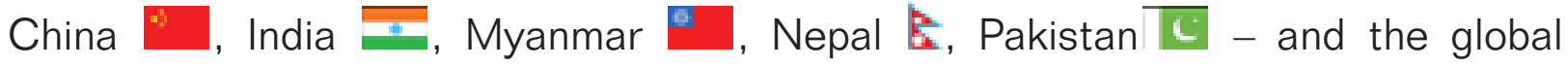
mountain community. Founded in 1983, ICIMOD is based in Kathmandu, Nepal, and brings together a partnership of regional member countries, partner institutions, and donors with a commitment for development action to secure a better future for the people and environment of the Hindu Kush-Himalayas. The primary objective of the Centre is to promote the development of an economically and environmentally sound mountain ecosystem and to improve the living standards of mountain populations. 


\title{
Voice of Mountain People Capacity Building of Community- based Organisations in Advocacy in the Hindu Kush-Himalayas
}

\author{
Workshop Report \\ Documentation of Conceptual Learning
}




\section{Internal Report}

\section{Copyright $(2) 2005$}

International Centre for Integrated Mountain Development

All rights reserved

\section{Published by}

International Centre for Integrated Mountain Development (ICIMOD)

G.P.O. Box 3226

Kathmandu, Nepal

\section{Prepared by}

Rosemary A. Thapa (Consultant Editor)

The views and interpretations in this paper are those of the author. They are not attributable to the International Centre for Integrated Mountain Development (ICIMOD) and do not imply the expression of any opinion concerning the legal status of any country, territory, city or area of its authorities, or concerning the delimitation of its frontiers or boundaries. 
Initiating a capacity building programme on advocacy strategies for community organisations in the countries of Bangladesh, India, Nepal, and Pakistan is a challenge. Advocacy as such is a relatively new concept, particularly in the mountain areas of these countries, and to date the concept has not been introduced into government institutions. In addition, civil society organisations are practicing advocacy in the way that they themselves understand.

This regional planning workshop was the first gathering to discuss advocacy in such depth. Due to the postponement of the workshop from September to November and the change of venue from Nepal to Bangladesh, some of the preparatory processes had to be repeated. The tolerance of the participants, facilitators, and ICIMOD colleagues is much appreciated and I would like to express my sincere gratitude to all the participants and supporters of this workshop for their patience, positive responses, and support.

In particular, I would like to acknowledge Dr. Yogesh Kumar, Dr. Shanta Thapalia, Mr. Chandi Prasad Bhatt, and Mr. Malik Fateh Khan for chairing some of the sessions; and Mr. Subhash Mehandapurkar for giving a summary note of all presentations. Contributions from presenters and other participants were equally important. I would also like to apologise for not being able to mention here all those whom I would like to thank.

I would also like to express my gratitude to Anupam Bhatia for his continuous encouragement. Similarly, I would like to acknowledge Dr. Gabriel Campbell, Director General of ICIMOD, and Dr. Binayak Bhadra, Former Director of Programmes, for their good wishes.

I would also like to acknowledge Mr. Anil Kumar Singh and Mr. Khagendra Siktel for their support in workshop preparation, facilitation, and report preparation. Similarly, my sincere appreciation goes to Mr. Moung Thowai Ching and other colleagues from Green Hill, Bangladesh, who hosted the workshop at the local level in Bangladesh.

Last but not least, I would like to acknowledge Ms. Phunstchok Tshering and Mr. Kiran Shrestha from ICIMOD for their invaluable support during the workshop in Chittagong.

\author{
Dr. Nani Ram Subedi \\ Coordinator \\ Decentralisation \& Local Governance \\ ICIMOD, Kathmandu \\ November 2003
}


This was the first regional planning workshop for the programme 'Capacity Building of Community-based Organisations in Advocacy Strategies in the Hindu Kush-Himalayas'. Before organising this workshop the preparatory phase of the programme was completed, the main output being the identification of potential programme partners. This workshop began the process of bringing potential partners together to collectively consider capacity building for community-based organisations working in their respective areas. The workshop's primary objective was to finalise future activities for capacity building programmes following a participatory approach.

Past lessons from different programmes and a baseline study commissioned by ICIMOD in 1998 indicate that the very concept of advocacy itself is new to many potential organisations working in the HKH region. Therefore, for conceptual clarity, the planning workshop also included sessions on sharing successful lessons from different programme countries.

Accordingly, the workshop incorporated six presentations from four countries. As participants commented, all these presentations were impressive and increased participants' knowledge about advocacy strategies. A summary of the conceptual sharing is presented in this report.

One day of the workshop was organised as a field visit and offered an opportunity for interaction with local organisations of Rangamati District of the Chittagong Hill Tracts. The objective was to familiarise participants with realities on the ground, at least in Rangamati District, following their discussions on the theoretical perspectives of advocacy. For example, participants had talked a lot about the Kaptai hydropower dam and the resulting displacement of the indigenous population from the area, but had never seen the actual lake.

The workshop also reviewed the proposed model for collaboration and framing of activities for capacity building in the coming years. Accordingly, workshop participants realised that case studies from potential areas play a vital role in the capacity building of communitybased organisations in advocacy. Therefore, the themes, areas and potential institutions to carry out case studies will be crucial for the programme. Participants discussed these ideas and drew important conclusions from the workshop. Chapter 4 of the report presents the conclusions. The programme is optimistic that the workshop conclusions will guide all its activities during 2004 and 2005.

The ultimate aim of capacity building of community-based organisations is to enhance local activists' capacity to frame an advocacy strategy to resolve issues that cause local people to suffer. Therefore, the workshop discussed current issues in the programme countries. When compiling common issues within the counties, poor local-level governance in mountain areas appeared to be the most common and compelling issue at present.

However, governance as such is a vague term, covering a wide range of issues and problems. It was necessary to 'unpack' the notion of governance in the local context. Issues such as equity in resource distribution, gender discrimination, the rights of indigenous people 
over natural resources, and displacement become very visible when the problem of local governance is unpacked. Therefore, advocacy strategies for the coming decade should focus on the most important parameters of governance at the local level.

The workshop also discussed the need to establish regional linkages among potential partner organisations to sustainably enhance advocacy capacities in the HKH region beyond the life of the programme. Participants greatly appreciated the idea of establishing a regional forum to supply a resource pool on advocacy. A four-member working committee (one member from each programme country) was formed to take up the necessary preparation work.

Finally, workshop participants agreed that community-based organisations can be the most effective and consolidated force for carrying out advocacy initiatives. Local-level activists generally lead members of community organisations in raising their voice against whatever forces are creating obstacles to achieving the rights of poor mountain people. Throughout this process, federations of community organisations should be responsible for providing intellectual and professional support. Therefore, workshop participants suggested inviting these organisations to participate in the programme in order to maintain such broad outreach at the local level. 


\section{Acronyms and Ahbreviations}

ADDCN

Al

AKRSP

ATREE

CBO

CEGG

CFP

CFUG

$\mathrm{CHT}$

DFO

DISHA

FECOFUN

GO

HIMAWANTI

$\mathrm{HKH}$

HRM

ICIMOD

INGO

LACC

MNCS

MTAP

NCAS

NEPAN

NFIWUAN

$\mathrm{NGO}$

NRM

NRSP

PLA

POWER

PRA

PRIA
Association of District Development Committees of Nepal

Advocacy Institute

Aga Khan Rural Support Programme (Pakistan)

Ashoka Trust for Research in Ecology and Environment

community-based organisation

Culture, Equity, Gender and Governance

community forest programme

community forest user group

Chittagong Hill Tracts

district forest officer

Analysis of Developing Initiatives for Social and Human Development

Federation of Community Forest Users, Nepal (an NGO)

government organisation

Himalayan Grassroots Women's Natural Resource Management Association

Hindu Kush-Himalayas

human resources management

International Centre for Integrated Mountain Development

international non-governmental organisation

Legal Assistance and Consultancy Centre

multinational corporate sector

Medium-term Action Plan

National Centre for Advocacy Studies

Nepal Participatory Action Network

National Federation of Irrigation Water Users Association Nepal

non governmental organisation

natural resource management

National Rural Support Programme

participatory learning and action

Participation of Women for their Real Representation

participatory rural apraisal

International Centre for Learning and Promotion of Participation and

Democratic Governance 
RAPE

RBA

RLEK

RSPN

SEWA

SLOT

SRISTI

SSI

SUTRA

ToR

ToT

UNNATI

VANI

VDC resist, apply, persuade and engage

rights-based approach

Rural Litigation and Education Kendra

Rural Support Programme Network

Self-employed Women's Association

strengths, limitations, opportunities, threats

Society for Research and Initiatives for Sustainable Technologies and Institutions

Social Science Institute

Society for Social Uplift Through Rural Action

terms of reference

training of trainers

Organisation for Development Education

Voluntary Action Network India

village development committee 


\section{Contents}

Acknowledgements

Executive Summary

Acronyms and Abbreviations

Chapter 1: Introduction to the Advocacy Programme

Background to ICIMOD's Advocacy Programme

Evolution of the Project Proposal

Strategies for Implementation

Preparatory Phase of the Project

Chpater 2: Concept, Theory and Practice of Advocacy

Chapter 3: Strategic Planning for Advocacy

$\begin{array}{ll}\text { Visualisation of a Planning Framework } & 17\end{array}$

Analysis of Systems and Structures 18

$\begin{array}{ll}\text { Operational Mechanisms for Advocacy } & 19\end{array}$

Assessment of the Existing System 19

Assessing Political Dynamics 20

Status of Social Justice and Human Rights 20

The Importance of Public Opinion $\quad 21$

Strengths, Limitation, Opportunity, Threat (SLOT) as a Planning Tool 21

\section{Chapter 4: Capacity Building}

Needs Assessment

Identification of Resource Persons 24

Literature Review 24

Partner Selection Process $\quad 25$

Geographical Areas $\quad 26$

Country-level Issues for Advocacy 27

Regional Issues $\quad 28$

Chapter 5: Learning from the Workshop 31

Conceptual Understanding 31

Workshop Conclusions $\quad 34$

Learning from the Workshop Evaluation 38

$\begin{array}{ll}\text { References } & 39\end{array}$

\section{Annexes}

Annex 1: Workshop Programme 41

Annex 2: List of Participants $\quad 45$ 